\title{
Emergency department utilization by people living with HIV released from jail in the US South
}

\author{
Alfredo G. Puing ${ }^{1}$, Xilong Li ${ }^{2}$, Josiah Rich ${ }^{3}$ and Ank E. Nijhawan ${ }^{2,4,5^{*}}$ (D)
}

\begin{abstract}
Background: Incarceration is disruptive to HIV care, often resulting in poor retention in care for people living with HIV (PLWH) after jail release. This gap in HIV care might result in potentially preventable emergency department (ED) utilization. We analyzed demographic, incarceration, socioeconomic and clinical data for PLWH released from the Dallas County Jail to the community (1450 incarcerations, 1155 unique individuals) between January 2011 and November 2013.
\end{abstract}

Results: The study population consisted of predominantly men (77\%), with a mean age of 39 years, $67 \%$ were black and $14 \%$ were Hispanic; half of the releasees visited the ED at least once during the first-year post-jail. In adjusted analyses, female gender, family awareness of HIV status, serious mental illness, and late engagement to HIV care were significantly associated with higher ED utilization. Compared to the general Dallas population, PLWH released from jail had a 5 -fold higher proportion of ED visits classified as related to substance use or mental health.

Conclusions: Further efforts are needed to improve the transition from incarceration to community-based HIV care, substance use disorder treatment and mental health services, and to directly address re-engagement in HIV care for out-of-care PLWH who visit the ED.

Keywords: Emergency department, HIV, Jail

\section{Introduction}

Approximately 6.9 million adults in the US were under correctional supervision in 2013 (Glaze \& Herberman, 2013). HIV/AIDS disproportionally affects the incarcerated population with rates up to three times higher than the general population (Bronson, 2017). In 2015, the HIV seroprevalence in state and federal prisons was $1.3 \%$ (Bronson, 2017), whereas in large urban jails, it was estimated to be between 1 to 6\% (Beckwith et al., 2012;

\footnotetext{
* Correspondence: Ank.Nijhawan@UTSouthwestern.edu

${ }^{2}$ Department of Clinical Sciences, University of Texas Southwestern Medical Center, Dallas, TX, USA

${ }^{4}$ Department of Internal Medicine, Division of Infectious Diseases, University of Texas Southwestern Medical Center, 5323 Harry Hines Blvd., Dallas, TX 75390-9169, USA

Full list of author information is available at the end of the article
}

Spaulding et al., 2015). During incarceration, antiretroviral therapy (ART) is for the most part readily available and many detainees achieve an undetectable viral load prior to release (Iroh, Mayo, \& Nijhawan, 2015). Nonetheless, PLWH face multiple barriers after transitioning from jail to their local communities which limit their reengagement in HIV care (Loeliger et al., 2018; Westergaard, Spaulding, \& Flanigan, 2013). For instance, it is estimated that only $36 \%$ of HIV-positive released detainees will present to an HIV provider within 6 months after release from jail or prison (Iroh et al., 2015).

This gap in HIV care may lead to increased utilization of acute care services, such as the emergency department (ED), in order to address needs like continuation of ART and treatment of non-emergent conditions. In a study evaluating ED utilization by individuals released 
from prison in Rhode Island, recently released persons presented to the ED mainly for evaluation and management of mental health disorders, substance use disorders, and ambulatory care conditions (Frank et al., 2013). Similarly, Meyer et al. examined ED utilization data from a cohort of HIV-positive individuals on ART released from prison and demonstrated that 1 out of 3 ED encounters were due to substance use, mental illness and/or social access issues (Meyer, Qiu, Chen, Larkin, \& Altice, 2013). Frequent and early ED visits in HIVpositive jail releasees have been linked to poor socioeconomic support (i.e. homelessness) and substance use (Boyd, Song, Meyer, \& Altice, 2015).

Although previous research studies on ED utilization following release from the criminal justice system have been informative, they have relied on the infrastructure of randomized controlled trials which provided increased oversight, readily available healthcare access, and scheduled discharge planning from prison to the community. Therefore, these studies may not reflect real-life conditions for most individuals released from jail. Another shortcoming of these prior studies is the limited healthcare network used to analyze the ED utilization among PLWH released from jail which likely misses a not insignificant number of outside-network ED encounters. Lastly, prior studies relied on small sample sizes that may not be representative of the entire population, and furthermore, could have be underpowered to detect different patterns of ED utilization among subgroups (Boyd et al., 2015; Khanna, Leah, Fung, Antoniou, \& Kouyoumdjian, 2019; Meyer et al., 2013).

We utilized a retrospective cohort study to provide a comprehensive assessment of ED utilization by matching data from HIV-positive released jail detainees (accounting for 1450 releases) with an extensive database of 90 hospitals in North Texas as well as with communitybased HIV clinic electronic data sources. Additionally, we characterized these ED encounters using the New York University (NYU) ED visit severity algorithm, a novel method to classify ED encounters including the identification of potentially avoidable visits (Ballard et al., 2010). The aims of our study were to (1) determine the prevalence, timing and predictors of ED utilization by HIV-positive individuals up to 12 months after release; (2) describe and compare the ED utilization between those who engaged and did not engage in HIV care after jail release; and (3) describe the primary reasons for ED visits, and whether or not they were potentially preventable.

\section{Methods}

\section{Study population}

This retrospective cohort study included all incarcerations among individuals with HIV at the Dallas County Jail (DCJ) that resulted in release to the community between January 1, 2011 and November 30, 2013. An incarceration was excluded from our sample if it did not result in a community release (e.g., transferred to prison or state jail) or if the inmate reported they planned to receive care with a provider outside of the Dallas Ryan White-funded clinic system. We included only Ryan White funded patients because the vast majority (93\% in our study) of patients who come through jail qualify for Ryan White services and receive HIV services form a Ryan White funded clinic. In addition, due to the Health Resources and Services Administration requirement for annual reporting on all clients using the encrypted unique client identifier (eUCI), we were able to systematically capture clinic visit data through the Ryan White Services report which would otherwise not be readily available. Post-release periods were excluded if they were $<90$ days before the end of the study period as per our previous approach to evaluate time to linkage to HIV care (Ammon et al., 2018). ED visits were tracked for 12 months following release from jail and including data through November 30, 2014, which marks the end of the study period. This study was approved by The University of Texas Southwestern Institutional Review Board.

In the DCJ, individuals are identified as HIV-positive if they disclose their HIV status during medical intake, if they are known to be HIV-positive from prior incarcerations, or if they have a positive HIV test result during incarceration. There are approximately 125 HIV-positive people ( $2 \%$ of population) in DCJ at any point in time, and HIV providers from Parkland Health and Hospital System (PHHS) are available 4 to 5 days per week. Of note, the majority of HIV-positive persons in DCJ are already known to have HIV at the time of entry (though date of diagnosis not routinely collected) with few new diagnoses given limited HIV testing during incarceration. During the study period, HIV discharge planning included an in-person case manager meeting while in jail, 1-week supply of medications provided upon request at release and a follow-up phone call from the case manager. In the Dallas metropolitan area, there is a large Ryan Whitefunded clinic system, including that operated by PHHS (providing care to over 5000 clinic patients per year during study period), and Prism Health (around 1500 patients per year during study period). The patient population that attends these clinics is predominately minority (approximately 50\% black, 25\% Hispanic), around 70\% male, and nearly $50 \%$ of the overall outpatient clinic population are men who have sex with men.

\section{Data sources}

A master data set was previously compiled from multiple sources, including the DCJ electronic medical record (Pearl, Business Computer Application), DCJ release 
data (Adult Information System), PHHS electronic medical record (Epic, Epic Systems Corporation), Prism Health clinic electronic medical record (Centricity, General Electronic Company), and Ryan White Service Report (RSR, used by HIV clinics for reporting to Health Resources and Services Administration). Initial matching of data was performed using an eUCI (described elsewhere) (Montague et al., 2016), with validation thorough manual review of jail and community electronic health records. Approximately $30 \%$ of the sample was not initially identified by eUCI matching alone, though all charts were manually reviewed for validation and additional data collection. Additional HIV-positive individuals, who were not matched using the eUCI method, were identified if "HIV" or "AIDS" was in the jail electronic health record problem list and validated through electronic chart review.

\section{Independent variables/predictors}

Demographic variables include age, race/ethnicity, and gender. Age (as of November 30, 2013) was calculated using date of birth from the jail medical record. Race was collected from the RSR and ethnicity from the jail and outpatient clinic datasets, with race/ethnicity redefined as non-Hispanic black, non-Hispanic white, or Hispanic. Gender was originally determined from the RSR and jail health record as female, male, or transgender. There were 14 incarcerations identified among transgender patients (all male to female), though due to this small size, gender at birth was used for the purposes of data analysis. HIV risk factor was extracted from the RSR, and narrowed down to history of injection drug use (IDU), men who have sex with men (MSM), or heterosexual/other. Individuals reporting both IDU and MSM were classified as IDU; those reporting both MSM and heterosexual risk were classified as MSM.

Marital status (ever married vs. other), family aware of HIV status (yes/no), and family supportive (yes/no) were obtained from jail case management documentation in Epic. Housing status was abstracted from the RSR and case management notes as a binary variable-stable/permanent vs. other. Whether someone was employed, unemployed, or on disability and self-reported history of sexual or physical abuse (yes/no) was obtained from case management notes. Alcohol use was condensed to a binary variable denoting at-risk alcohol use, defined as $\geq 14$ drinks per week for men and $\geq 7$ drinks per week for women, or not. A binary composite variable, "stimulant/ opioid use," was created for any reported use of cocaine, crack cocaine, methamphetamines, opioids and/or heroin. We created this combined variable due to our experience that these substances are associated with difficulty linking to care, and to separate them out from marijuana use, which is very prevalent in this population.
Mental illness was collected as a binary composite variable with "serious mental illness" defined as having a diagnosis of bipolar disorder, psychosis, and/or schizophrenia. Self-reported information on prior use of an HIV clinic, prior prescription of ART, and prior adherence to ART before incarceration was available from case management and electronic medical record (EMR) data.

Income level was abstracted from the RSR as an ordinal variable based on percentage of federal poverty level (\%FPL) using the earliest occurrence in the dataset for each individual. Health insurance coverage was collected from Epic and categorized as commercial insurance, Medicaid, Medicare, "charity" insurance (including Ryan White and local programs), or missing. Both income level and insurance coverage had significant amounts of missing data, and, since they were collected in community outpatient settings, the missing categories are collinear with not liking to care. Additionally, the income variable had a very limited range of responses (i.e., virtually every subject was under FPL). Due to these limitations, income and insurance were not included in the final analysis. Linkage to HIV care (yes/no) was defined as attending an ambulatory care visit with a Ryan White-funded HIV provider in Dallas County after release, as documented in the RSR and/or provider EMRs. If there was no documentation of such a visit, it was counted as failure to link to care for that incarceration. Though it is possible that individuals were engaged in care prior to incarceration and have a brief enough incarceration to still meet Ryan White criteria for retention in care ( 2 visits within 12 months $>90$ days apart), we examined linkage to care at before and after 90 days after jail release given high baseline rates of ART nonadherence and post-release treatment interruption. In fact, given the disruptive impact of jail on a patient's health, we generally recommend a visit within 30 days of release for all incarcerated PLWH.

\section{Outcomes}

The primary outcome was post-release ED utilization, defined as frequency of ED visits within the first 12 months after jail release. This was categorized as no ED visit, 1 to 2 ED visits, and more than $3 \mathrm{ED}$ visits to one or more of the 90 local hospitals that form part of the Dallas-Fort Worth Hospital Council Foundation (DFWHC). We chose to categorize ED visits rather than use them as a continuous variable since data would be skewed by some very heavy ED utilizers. We selected these three categories based on the literature (Frank et al., 2013) and the distribution of our data. Additionally, timing of first ED visit by linkage to HIV care, and NYU ED visit classification were described in order to further characterize ED utilization. We plotted daily cumulative percentage of having an ED 
visit or HIV clinic visit for the time frame post-release to first HIV clinic visit and first ED visit, separately, with censoring at the time of reincarceration or at the end of the study period. Linkage to HIV care was also classified in 3 categories: early linkage to HIV care (first HIV clinic visit before 90 days from jail release), late linkage to HIV care (first HIV clinic visit after 90 days from jail release), and no linkage to HIV care (no HIV clinic visit during the follow up period). The NYU ED visit severity algorithm classified the encounters into three main categories: emergent, non-emergent, and other (mental health related, alcohol related, substance abuse related, injury and unclassified). Emergent visits are further divided into three additional categories of preventability: ED care needed not preventable, ED care needed preventable, and primary care treatable (Ballard et al., 2010). ED utilization patterns among PLWH were compared to those of the general Dallas County population from 2010 to 2012 published by the DFWHC (Sharma, Seals, Jenkins, Isaacs, \& Anderson, 2017).

\section{Statistical analyses}

The main unit of analysis was each incarceration during the study period. Cross-tabular frequencies were used to calculate baseline characteristics. Univariate analyses were conducted, and associations between each independent variable and ED utilization as a categorical outcome (no ED visit, 1-2 ED visits, $>3$ ED visits) were presented by an odds ratio with Wald confidence intervals. Subsequently, a multivariate ordinal logistic regression model was built by including all variables with a priori variables of age, gender, and length of incarceration included. The final model was constructing using a backward elimination selection method. Variables were retained in the model if $p<0.20$. Multicollinearity was identified between the variables serious mental illness, stimulant/opioid use, and employment status, therefore employment was removed from the final multivariate model. In addition, though we present only the results of the multivariate model using incarceration as the unit of analysis, we also used a generalized linear model (GEE) to account for intra-subject correlation. Given similar results, this model is not presented in the results section.

\section{Missing data}

Given the availability of comprehensive data sets from the jail, Ryan White funded clinics and DFWHC, if data were absent for HIV clinic visits and for ED visits, it was assumed that missing $=$ no visit. For other variables, especially if data were available from more than one source, e.g. housing (case management notes and Ryan White Services report), there were relatively few missing datapoints. However, for other variables such as income and insurance, which were only collected in the outpatient clinic setting (not in jail), there were a lot of missing data (up to 29\%) which were not missing at random, therefore missing was treated as a separate category for these variables. All statistical analyses were run using SAS, version 9.4 (SAS Institute Inc., Cary, NC).

\section{Results}

Of 2473 incarcerations of HIV-positive individuals identified during the study period, 669 were excluded for not being released to the community, 163 planned to seek care outside of the Dallas Ryan White-funded system, and 188 were excluded due to having less than 90 days of follow-up in the study period. The final study population consisted of 1450 incarcerations involving 1155 unique individuals.

The general characteristics of the study population are shown in Table 1. The majority of incarcerations were among Blacks (68\%), the mean age was 39.1 years, and $77 \%$ were male. Only about one quarter reported a stable/permanent living situation, and employment was $8.3 \%$ overall. Reported use of any illicit drug was $64 \%$, with the most prevalent drug being cannabis (42\%). Over half of the cohort reported a history of mental illness (50.1\%). In terms of prior HIV care, 63\% reported prior ART prescriptions, but only $40 \%$ of the overall cohort reported that they had been adherent. Overall, $43 \%$ of the cohort did not present to an HIV clinic during the year after release to the community with $34 \%$ linked to HIV care within 90 days of jail release, and an additional $23 \%$ linked to HIV care after 90 days from release to the community.

\section{Outcomes}

The overall proportion of the study population with at least one ED visit after jail release was 53\% (Fig. 1). Among the $765 \mathrm{HIV}$-positive jail released detainees that presented to the ED, 463 (60.5\%) had 1 to 2 ED visits in the follow up period, whereas 302 (39.5\%) had 3 or more ED visits. In the univariate analysis, the major predictors of ED utilization were female gender, being married, family awareness of HIV status, receiving disability benefits, prior physical and sexual abuse, mental illness, substance use, prior HIV care before incarceration, and late engagement to HIV care after jail release. Hispanics were significantly less likely to present to the ED than whites (Table 2).

In multivariate logistic regression analysis, female patients were significantly more likely to present to the ED than male patients (aOR 1.30 [95\% CI: 1.00-1.69]). Family awareness of HIV status, severe mental illness, and late engagement to HIV care after jail release were all significantly associated with higher ED utilization. Conversely, Hispanic ethnicity and adherence to ART prior 
Table 1 Baseline characteristics of all releases of HIV-positive individuals released from Dallas County Jail to the community, January 2011-November 2013

\begin{tabular}{|c|c|c|c|c|}
\hline Demographics and incarceration & $\begin{array}{l}\text { No ED visits } \\
\boldsymbol{n}=685(\%)\end{array}$ & $\begin{array}{l}1 \text { to } 2 \text { ED visits } \\
\boldsymbol{n}=463(\%)\end{array}$ & $\begin{array}{l}\text { > } 3 \text { ED visits } \\
\boldsymbol{n}=302(\%)\end{array}$ & $\begin{array}{l}\text { Total } \\
\boldsymbol{N}=1450(\%)\end{array}$ \\
\hline Age $($ mean $\pm S D)$ & $39.1 \pm 10.6$ & $38.2 \pm 10.6$ & $40.4 \pm 11$ & $39.1(30.2-47.7)$ \\
\hline Male (\%) & 81.0 & 76.5 & 67.9 & 76.8 \\
\hline \multicolumn{5}{|l|}{ Race/ethnicity } \\
\hline White & 18.5 & 17.1 & 22.9 & 19.0 \\
\hline Black & 64.7 & 69.3 & 70.9 & 67.4 \\
\hline Hispanic & 16.8 & 13.6 & 6.3 & 13.6 \\
\hline Median incarceration length [IQR] (days) & $5[1-18]$ & $6[1-18]$ & 7 [2-23] & $6[1-19]$ \\
\hline \multicolumn{5}{|l|}{ HIV risk factor } \\
\hline $\mathrm{IDU}+\mathrm{MSM}$ & 2.5 & 4.3 & 3.0 & 3.2 \\
\hline IDU (non-MSM) & 5.6 & 7.6 & 11.6 & 7.5 \\
\hline MSM (non-IDU) & 31.7 & 30.7 & 25.5 & 30.1 \\
\hline All others & 60.3 & 57.5 & 59.9 & 59.3 \\
\hline \multicolumn{5}{|l|}{ SES/housing } \\
\hline Ever married & 19.9 & 23.1 & 30.8 & 23.2 \\
\hline Family aware of HIV status & 47.5 & 55.3 & 62.3 & 53.0 \\
\hline Family supportive of HIV status & 57.5 & 60.5 & 61.6 & 59.3 \\
\hline Stable/permanent housing & 27.7 & 26.1 & 21.9 & 26.0 \\
\hline \multicolumn{5}{|l|}{ Source of Income } \\
\hline Employed & 9.6 & 8.2 & 5.3 & 8.3 \\
\hline Disability benefits & 19.9 & 30.2 & 39.7 & 27.3 \\
\hline All others & 70.5 & 61.6 & 55.0 & 64.4 \\
\hline History of physical/sexual abuse & 21.2 & 23.8 & 32.5 & 24.3 \\
\hline \multicolumn{5}{|l|}{ Income level } \\
\hline Percent at or below $100 \% \mathrm{FPL}$ & 64.7 & 72.6 & 74.5 & 69.2 \\
\hline Percent above $100 \% \mathrm{FPL}$ & 6.1 & 5.6 & 3.3 & 5.4 \\
\hline Unknown or missing & 29.2 & 21.8 & 22.2 & 25.4 \\
\hline \multicolumn{5}{|l|}{ Insurance coverage } \\
\hline Commercial & 2.3 & 1.7 & 3.0 & 2.3 \\
\hline Medicare & 10.7 & 13.4 & 13.6 & 12.1 \\
\hline Medicaid & 16.8 & 30.0 & 44.7 & 26.8 \\
\hline Charity & 42.5 & 37.8 & 27.2 & 37.8 \\
\hline Missing & 27.7 & 17.0 & 11.5 & 21.0 \\
\hline \multicolumn{5}{|l|}{ Substance use } \\
\hline At-risk alcohol use & 4.8 & 5.6 & 6.6 & 5.5 \\
\hline Tobacco use & 48.8 & 58.1 & 67.2 & 55.6 \\
\hline Any illicit drug use & 58.0 & 66.7 & 67.2 & 62.8 \\
\hline Cannabis & 39.9 & 46.7 & 40.7 & 42.2 \\
\hline Cocaine & 24.2 & 24.6 & 34.4 & 26.5 \\
\hline Crack cocaine & 15.3 & 16.4 & 26.8 & 18.1 \\
\hline Methamphetamines & 12.4 & 13.6 & 15.2 & 13.4 \\
\hline Heroin & 5.0 & 7.3 & 12.2 & 7.2 \\
\hline Stimulant/opioid use & 40.6 & 41.3 & 54.0 & 43.6 \\
\hline
\end{tabular}


Table 1 Baseline characteristics of all releases of HIV-positive individuals released from Dallas County Jail to the community, January 2011-November 2013 (Continued)

\begin{tabular}{|c|c|c|c|c|}
\hline Demographics and incarceration & $\begin{array}{l}\text { No ED visits } \\
\boldsymbol{n}=685(\%)\end{array}$ & $\begin{array}{l}1 \text { to } 2 \text { ED visits } \\
\boldsymbol{n}=463(\%)\end{array}$ & $\begin{array}{l}>3 \text { ED visits } \\
\boldsymbol{n}=302(\%)\end{array}$ & $\begin{array}{l}\text { Total } \\
\boldsymbol{N}=1450(\%)\end{array}$ \\
\hline \multicolumn{5}{|l|}{ Mental illness } \\
\hline Any mental illness & 43.4 & 52.7 & 61.3 & 50.1 \\
\hline Bipolar disorder & 23.8 & 30.0 & 36.1 & 28.3 \\
\hline Schizophrenia/psychosis & 13.6 & 18.8 & 21.2 & 16.8 \\
\hline Anxiety & 8.5 & 8.4 & 11.3 & 9.0 \\
\hline Depression & 26.0 & 34.3 & 38.4 & 31.2 \\
\hline PTSD & 2.0 & 3.2 & 6.6 & 3.4 \\
\hline Serious mental illness & 28.6 & 34.8 & 42.7 & 33.5 \\
\hline \multicolumn{5}{|l|}{ HIV care } \\
\hline Reported prior HIV clinic & 56.9 & 64.2 & 61.6 & 60.2 \\
\hline Prescribed ART before incarceration & 62.3 & 63.1 & 64.6 & 63.0 \\
\hline Adherent to ART before incarceration & 42.3 & 39.7 & 38.4 & 40.7 \\
\hline First viral load in jail undetectable & 35.7 & 28.4 & 27.7 & 31.6 \\
\hline Last viral load in jail undetectable & 38.4 & 31.6 & 34.2 & 35.3 \\
\hline \multicolumn{5}{|l|}{ Linkage to care } \\
\hline No clinic visit after release & 46.3 & 39.3 & 40.1 & 42.8 \\
\hline First clinic visit 0-90 days after release & 33.1 & 36.3 & 30.8 & 33.7 \\
\hline First clinic visit $>90$ days after release & 20.6 & 24.4 & 29.1 & 23.6 \\
\hline
\end{tabular}

to incarceration were significant predictors of less ED utilization in the multivariate analysis (Table 2).

ED utilization was high shortly after transitioning to the community with $27 \%$ of the entire cohort having at least one $\mathrm{ED}$ visit by 90 days after release. Furthermore, there was higher percentage of first ED visits than first clinic visits during the first 30 days after jail release (Fig. 1 enlargement). The majority of first ED visits were from patients that had delayed linkage to HIV care ( $>90$ days postrelease) or had no linkage to HIV care whatsoever (Fig. 2).
Our cohort had a total of 2771 ED visits in the 12 months following release from jail. Only 15.4\% ED visits resulted in hospitalizations. Using the NYU ED classification algorithm, 29\% of ED visits were emergent, 12.9\% were non-emergent, $14.5 \%$ were unclassified and the remainder were either related to injury (15.8\%), mental health (6.8\%), alcohol use (2.8\%), or substance use $(2.8 \%)$ (Fig. 3a). Compared to the general population of Dallas County, our study population lower 'emergent-not preventable' causes for their ED visits and a higher

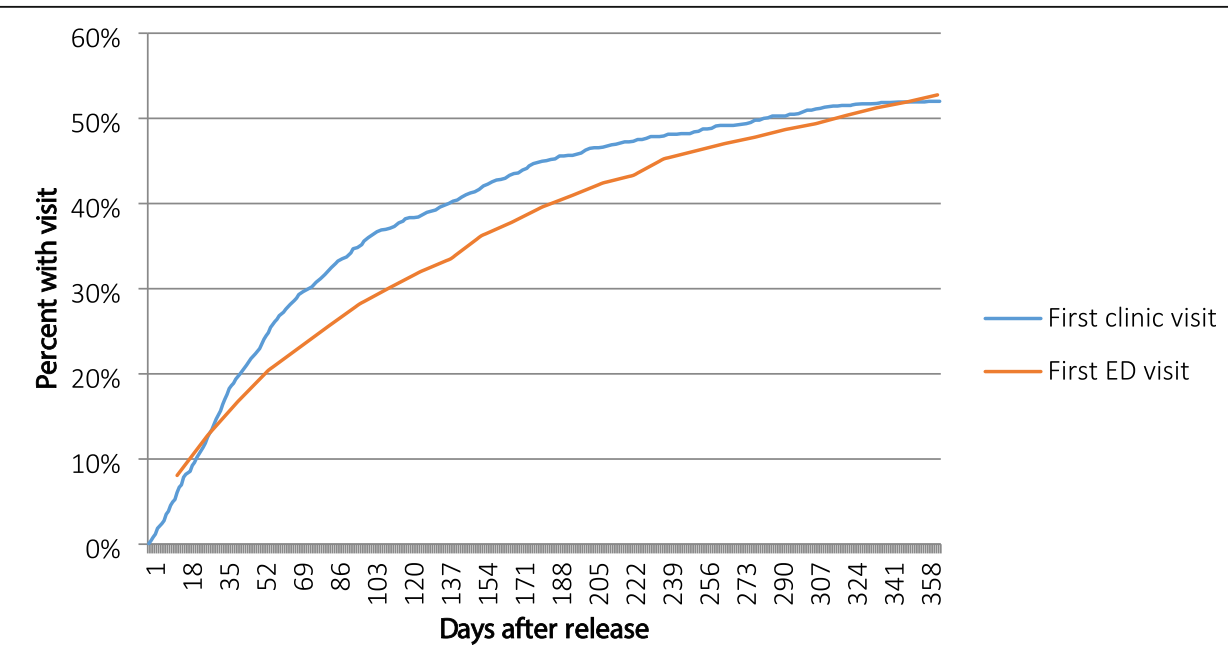

Fig. 1 Percentage with first HIV clinic visit and first ED visit after jail release. HIV=Human Immunodeficiency Virus, ED = Emergency Department 
Table 2 Univariate and multivariate predictors of ED utilization

\begin{tabular}{|c|c|c|c|c|}
\hline \multirow[t]{2}{*}{ Independent variable } & \multicolumn{2}{|l|}{ Univariate analysis } & \multicolumn{2}{|l|}{ Multivariate analysis } \\
\hline & Unadjusted OR (95\% Cl) & $\boldsymbol{p}$ value & Adjusted OR (95\% Cl) & $\boldsymbol{p}$ value \\
\hline \multicolumn{5}{|l|}{ Demographics and incarceration } \\
\hline \multicolumn{5}{|l|}{ Race/ethnicity } \\
\hline White & (Reference) & - & (Reference) & - \\
\hline Black & $0.96(0.75-1.24)$ & 0.76 & $1.04(0.80-1.35)$ & 0.78 \\
\hline Hispanic & $0.53(0.37-0.76)$ & 0.0004 & $0.61(0.42-0.87)$ & 0.007 \\
\hline Age (per 5 years in units) & $1.02(0.98-1.07)$ & 0.30 & - & - \\
\hline Female gender (vs. male) & $1.66(1.32-2.08)$ & $<0.0001$ & $1.30(1.00-1.69)$ & 0.05 \\
\hline Days of incarceration & $1.002(1.000-1.004)$ & 0.10 & - & - \\
\hline \multicolumn{5}{|l|}{ HIV risk factor } \\
\hline Heterosexual & (Reference) & - & - & - \\
\hline MSM (non-IDU) & $0.90(0.72-1.11)$ & 0.32 & $0.73(0.51-1.06)$ & 0.25 \\
\hline IDU & $1.60(1.17-2.20)$ & 0.004 & $0.73(0.51-1.04)$ & 0.21 \\
\hline \multicolumn{5}{|l|}{ SES/housing } \\
\hline Ever married & $1.51(1.20-1.89)$ & 0.0004 & $1.25(0.98-1.60)$ & 0.08 \\
\hline Family aware of HIV status & $1.56(1.28-1.89)$ & $<0.0001$ & $1.32(1.06-1.65)$ & 0.02 \\
\hline Family supportive of HIV status & $1.14(0.94-1.39)$ & 0.70 & - & - \\
\hline Stable housing & $0.82(0.65-1.02)$ & 0.07 & - & - \\
\hline \multicolumn{5}{|l|}{ Source of income } \\
\hline Employed (vs. other) & $0.84(0.58-1.21)$ & 0.35 & - & - \\
\hline Disability benefits (vs. other) & $2.04(1.64-2.54)$ & $<0.0001$ & - & - \\
\hline h/o physical/sexual abuse & $1.49(1.19-1.86)$ & 0.0005 & $1.20(0.94-1.54)$ & 0.15 \\
\hline \multicolumn{5}{|l|}{ Substance use } \\
\hline At-risk alcohol use & $1.28(0.84-1.95)$ & 0.25 & - & - \\
\hline Tobacco use & $1.74(1.43-2.12)$ & $<0.0001$ & - & - \\
\hline Any illicit drug use & $1.42(1.16-1.74)$ & 0.0007 & - & - \\
\hline Cannabis & $1.11(0.91-1.35)$ & 0.30 & - & - \\
\hline Club drug & $1.14(0.78-1.66)$ & 0.50 & - & - \\
\hline Cocaine & $1.37(1.10-1.70)$ & 0.005 & - & - \\
\hline Crack cocaine & $1.62(1.26-2.07)$ & 0.0001 & - & - \\
\hline Heroin & $2.09(1.45-3.01)$ & $<0.0001$ & - & - \\
\hline Opiates & $1.85(0.56-6.17)$ & 0.32 & - & - \\
\hline Methamphetamines & $1.19(0.90-1.57)$ & 0.23 & - & - \\
\hline Prescription medications & $1.19(0.49-2.90)$ & 0.70 & - & - \\
\hline Stimulant/opioid use & $1.39(1.14-1.68)$ & 0.001 & $1.07(0.86-1.34)$ & 0.06 \\
\hline \multicolumn{5}{|l|}{ Mental illness } \\
\hline Any mental illness & $1.70(1.40-2.07)$ & $<0.0001$ & - & - \\
\hline Bipolar & $1.55(1.26-1.92)$ & $<0.0001$ & - & - \\
\hline Schizophrenia/psychosis & $1.52(1.18-1.96)$ & 0.001 & - & - \\
\hline Anxiety & $1.22(0.87-1.70)$ & 0.24 & - & - \\
\hline Depression & $1.56(1.27-1.92)$ & $<0.0001$ & - & - \\
\hline PTSD & $2.54(1.50-4.31)$ & 0.0005 & - & - \\
\hline Serious mental illness & $1.57(1.28-1.92)$ & $<0.0001$ & $1.28(1.02-1.61)$ & 0.03 \\
\hline
\end{tabular}


Table 2 Univariate and multivariate predictors of ED utilization (Continued)

\begin{tabular}{|c|c|c|c|c|}
\hline \multirow[t]{2}{*}{ Independent variable } & \multicolumn{2}{|l|}{ Univariate analysis } & \multicolumn{2}{|l|}{ Multivariate analysis } \\
\hline & Unadjusted OR (95\% Cl) & $\boldsymbol{p}$ value & Adjusted OR (95\% Cl) & $\overline{p \text { value }}$ \\
\hline \multicolumn{5}{|l|}{ Prior HIV care } \\
\hline Prior HIV clinic before incarceration & $1.23(1.01-1.50)$ & 0.043 & - & - \\
\hline Prescribed ART before incarceration & $1.07(0.87-1.30)$ & 0.53 & - & - \\
\hline Adherent to ART before incarceration & $0.88(0.72-1.07)$ & 0.21 & $0.77(0.62-0.95)$ & 0.01 \\
\hline ART prescribed in jail & $0.87(0.71-1.07)$ & 0.19 & - & - \\
\hline \multicolumn{5}{|l|}{ Linkage to care } \\
\hline Clinic visit 0-90 days after release & (Reference) & & (Reference) & \\
\hline Clinic visit > 90 days after release & $1.31(1.01-1.69)$ & 0.0018 & $1.33(1.02-1.73)$ & 0.04 \\
\hline No clinic visit after release & $1.13(0.90-1.42)$ & 0.35 & $0.80(0.63-1.01)$ & 0.06 \\
\hline
\end{tabular}

Abbreviations: ED Emergency Department, CI Confidence Interval, HIV Human Immunodeficiency Virus, MSM Men who have sex with men, IDU Injection drug use, PTSD Post-traumatic stress disorder, ART Anti-retroviral therapy

proportion of ED visits related to substance use, alcohol or mental health (Fig. 3b). The NYU ED classification was compared within the three different linkage to HIV care groups (early, late or no linkage to HIV care) obtaining similar percentages (data not shown).

\section{Discussion}

Early and frequent emergent department utilization occurred among PLWH recently released from a large urban jail in the South. In our cohort, an initial visit to the ED visit was more common than first attending an HIV clinic visit during the first month after jail release. Almost one-quarter of the jail releasees visited the ED at least once during the first 90 days following community reentry and over half of the entire cohort had at least one post-release ED visit within a year of release. Among the individuals who visited the ED, four out of ten had three or more ED encounters. These numbers reflect the substantial burden of high ED utilization immediately following jail release and raises the question of whether some visits could be prevented.

Compared to other groups released from incarceration, PLWH had similarly high rates of ED utilization (Frank et al., 2013), despite that PLWH typically receive care in a patient centered medical home (Friedman, Crowley, Howard, \& Pavel, 2015). Compared to the general population of Dallas County (Sharma et al., 2017), ED visits related to substance use, alcohol or mental health were 5 times more common among PLWH released from jail than the general population. PLWH recently released from jail also had a higher proportion of ED visits resulting in hospital admission than the general population.

Our study confirms and extends the literature by incorporating regional ED data which allows us to more comprehensively estimate the burden of ED utilization by PLWH after jail release. In accordance with previous studies (Boyd et al., 2015; Frank et al., 2013; Khanna et al., 2019; Meyer et al., 2013), individuals released from incarceration who engaged late into HIV care (first HIV

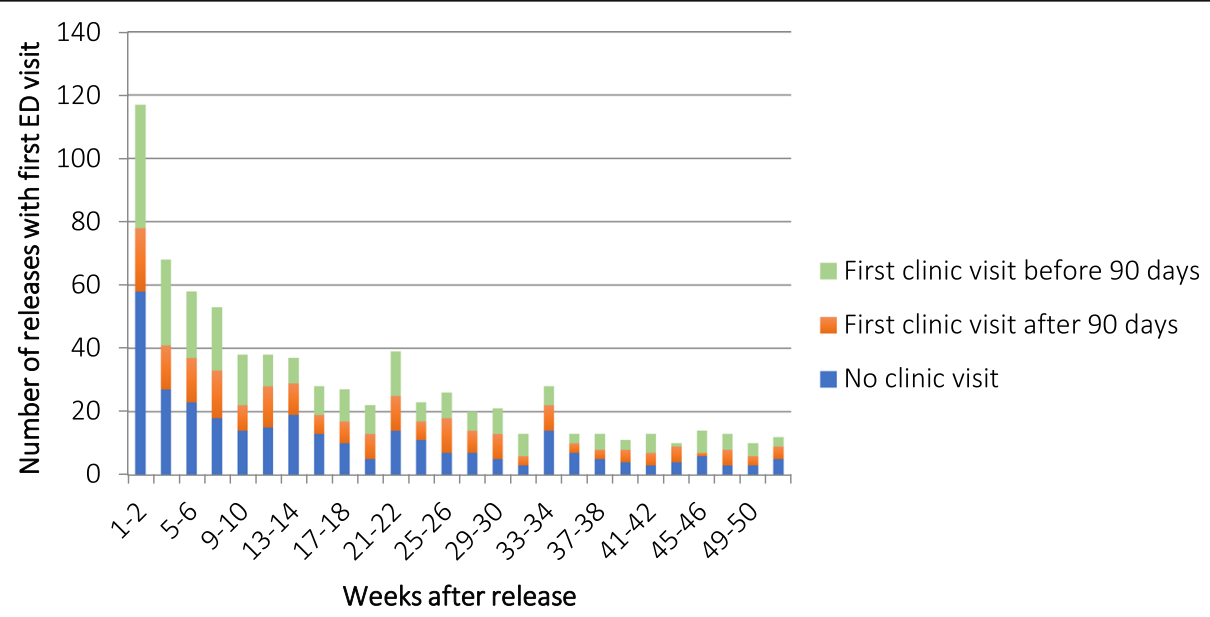

Fig. 2 Timing of first ED visit by HIV care engagement group. HIV=Human Immunodeficiency Virus, ED = Emergency Department 

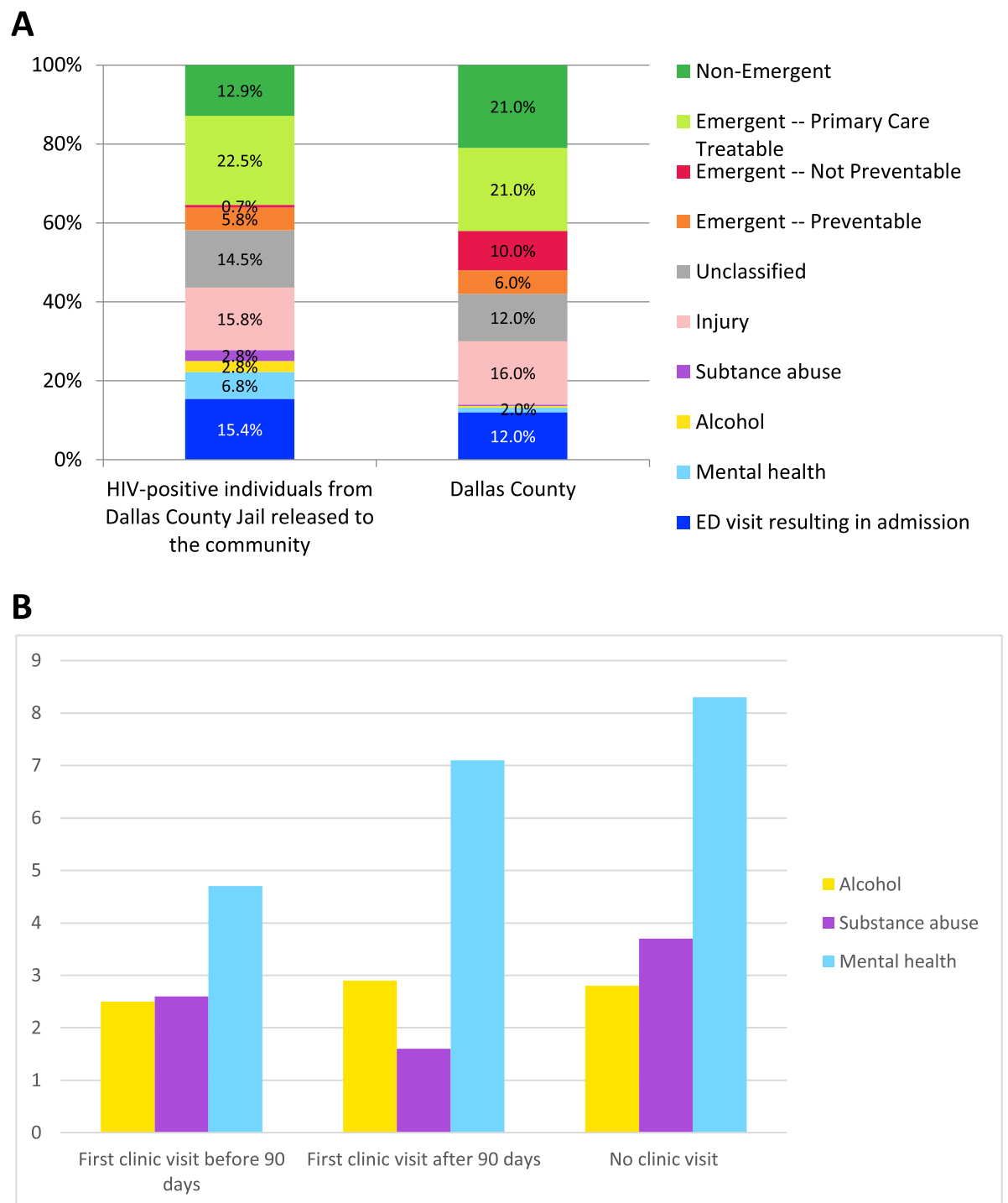

Fig. 3 a NYU ED visit categorization, HIV-positive released jail detainees versus general Dallas county population. Dallas County data adapted from Sharma S, et al. High frequency patient analysis to identify disparities associated with emergency department utilization in Dallas County. Texas Public Health Journal. 2017;69:19-29; NYU=New York University, ED = Emergency Department, HIV=Human Immunodeficiency Virus. b NYU ED categorization for alcohol, substance abuse and mental health by HIV care engagement group

clinic visit after 90 days from jail release) visited the ED earlier and more frequently than the 'early linkers' (first HIV clinic visit before 90 days from jail release). Furthermore, late linkage to HIV care was an independent predictor of high ED utilization in our multivariate analysis after adjusting for demographic characteristics, socioeconomic status, mental health, substance use and prior engagement in HIV care. Our results highlight similar patterns of health care utilization compared to the northeastern US and Canada, but on a greater scale, incorporating data from a large metropolitan area in the Southern United States, a region disproportionally affected by the HIV/AIDS epidemic with fewer social services and overall worse HIV outcomes.
In our study, we found that mental health and substance use disorder disproportionally impact PLWH after jail release, consistent with the existing literature (Boyd et al., 2015; Frank et al., 2013; Khanna et al., 2019; Meyer et al., 2013). According to the NYU ED visit severity algorithm, $10 \%$ of all ED visits in our cohort were related to mental health and substance use disorder. Additionally, serious mental illness was a statistically significant predictor of high ED utilization in our multivariate analysis. In other comparisons of ED utilization between ex-prisoners and the general population, Frank et al. demonstrated that people released from prison in Rhode Island were more likely to have an ED visit for substance use and psychiatric comorbidities, when 
compared to the general population (Frank et al., 2013). In particular, PLWH who have mental health and/or substance use disorders have been identified as high utilizers of ED services in the period immediately following release from incarceration. Boyd et al. evaluated a cohort of $71 \mathrm{PLWH}$ in the 12 months following jail release and demonstrated that substance use not only accounted for a high percentage (31\%) of ED visits, but was also associated with early and frequent ED utilization after release (Boyd et al., 2015). In a study by Meyer et al., the cumulative burden of psychiatric illness was also positively correlated with frequent ED visits by PLWH released from prison (Meyer et al., 2013). Our study goes beyond the existing data to demonstrate that released PLWH who present late ( $>90$ days) to HIV clinic or not at all, experience an increasing proportion of ED visits related to mental health issues.

Incarcerated women constitute another vulnerable group in the correctional system. They represent the fastest growing population in the criminal justice system and account for an increasing proportion of newly diagnosed HIV cases (Maruschak, 2015; Subramanian, Henrichson, \& Kang-Brown, 2015). Women living with HIV who are incarcerated are also more likely to suffer from substance use, depression and to be victims of past physical and sexual abuse (Mignon, 2016). Criminal justiceinvolved women are also more likely to be frequent ED utilizers than males (Meyer et al., 2013). Health services for incarcerated women are often not gender-specific nor individualized to meet the particular psychosocial needs of women. Trauma-informed care (TIC) has emerged as an approach to healthcare that incorporates safety, trust, peer support, collaboration, empowerment, and cultural perspectives to improve quality of care and the patient experience, thereby increasing longitudinal engagement of marginalized and hard-to-reach patients, such as those with criminal justice system exposure (Chaudhri, Zweig, Hebbar, Angell, \& Vasan, 2019). Implementation of TIC in the vulnerable and high-risk HIV jail population might improve healthcare quality and engagement into HIV care after correctional release and at time of ED evaluation.

Other independent predictors of ED utilization in our multivariate model were family being aware of HIV status (higher ED visits) and Hispanic ethnicity (lower ED visits). It is possible that PLWH who have disclosed their HIV status to their relatives have stronger family support which is a facilitator of health care access (Bracken, Hilliard, McCuller, \& Harawa, 2015). The association between Hispanic ethnicity and fewer ED visits may be related to higher rates of post-release linkage to HIV care among Hispanics in our study, as we have discussed in our previous publication, and correlates with lower proportions with mental illness and substance use among Hispanics in our study (Ammon et al., 2018).
Several interventions focused on improving retention in routine HIV care after incarceration have been evaluated. Transitional case management programs and peer navigation have been shown to help PLWH engage in health care after jail release and improve HIV treatment outcomes (Althoff et al., 2013; Sayles, Wong, Kinsler, Martins, \& Cunningham, 2009; Spaulding et al., 2013). However, conflicting data exist, and some studies have shown no benefit of intensive management interventions over control groups on post-release outcomes, though these programs had very high linkage to care in the control arm and high recidivism rates, making post-release outcomes more challenging to interpret (MacGowan et al., 2015; Wohl et al., 2011, 2017). The expansion of Medicaid is an important tool for improving care delivery for individuals leaving jail or prison (Guyer, Serafi, Bachrach, \& Gould, 2019), though individuals released in states which have not expanded Medicaid, particularly low-income individuals, face additional barriers (Grodensky et al., 2018; Washington Post Editorial Board, 2019). Ending the Medicaid exclusion for people under correctional supervision would allow for continuous access to mental health and substance abuse treatment which is associated with lower rates of recidivism (Pew Charitable Trusts, 2011) and could impact healthcare utilization. However, our findings indicate that half of the releasees with the highest number of ED visits (3 or more) were Medicaid beneficiaries which may indicate that Medicaid facilitates health care access but does not necessarily optimize health care utilization. Future interventions should also focus on ED encounters as opportunities to reengage PLWH into HIV care. As demonstrated by a study of a routine opt-out HIV testing program in a large Houston emergency room, care coordination efforts initiated in the emergency room improve engagement, retention, and virologic suppression in previously diagnosed patients (Flash et al., 2015). Lastly, effective reforms to address the mass incarceration problem in the US would also have a significant impact on the burden of ED misuse after prison or jail release by reducing the exposure to the destabilizing post-release period (Dumont, Brockmann, Dickman, Alexander, \& Rich, 2012).

Despite the number of strengths of this research project, our study has several limitations. First, our study involves data collected in a single county jail which may not be generalizable to other settings, although we found similarities between our results and other cohorts of PLWH released from correctional supervision. Second, it is possible that some of the HIV-positive released jail detainees received HIV care outside the Ryan White care system in the Dallas metropolitan area (although we excluded patients who mentioned that they planned to do so), potentially resulting in decreased observed rates of 
linkage to HIV care in this study. Lastly, there is a sizeable proportion of patients with ED visits unclassified by the NYU ED visit severity algorithm (14.5\%) which were not further characterized. This is similar to other studies using this algorithm and a limitation to using this approach (Johnston, Allen, Melanson, \& Pitts, 2017).

\section{Conclusions}

In this study using a comprehensive database of hospitals, jail health data and data from community-based HIV clinics in North Texas, we demonstrated that high ED utilization by PLWH occurs shortly and frequently after jail release. In this population, disproportionally impacted by the HIV/AIDS epidemic in the United States, we identified a higher proportion of ED encounters for mental health and substance use disorders than the general population. Similarly, we demonstrated that women, persons with serious mental illness and late engagers in HIV-care are high utilizers of emergent department resources. Interventions to improve postrelease linkage to HIV care are key to decrease the burden of ED misuse and should be focused on vulnerable populations such as women, patients with severe mental health and substance use disorder. These actions are important in the efforts to end the HIV/AIDS epidemic.

\section{Abbreviations \\ PLWH: People living with HIV; ED: Emergency department; HIV: Human immunodeficiency virus; AIDS: Acquired Immune Deficiency Syndrome; ART: Antiretroviral therapy; NYU: New York University; DCJ: Dallas County Jail; PHHS: Parkland Health and Hospital System; RSR: Ryan White Service Report; eUCl: Encrypted unique client identifier; IDU: Injection drug use; MSM: Men who have sex with men; EMR: Electronic medical record; FPL: Federal poverty level; DFWHC: Dallas Fort Worth Hospital Council; US: United States; TIC: Trauma-informed care \\ Acknowledgements \\ The authors would like to acknowledge the Dallas Fort Worth Hospital Council Foundation for assisting in data collection of Emergency Department utilization and use of the New York University algorithm.}

\section{Authors' contributions}

AP developed the research questions, designed the data analysis plan, contributed to writing the manuscript, developed all tables and figures, $\mathrm{XL}$ compiled and analyzed the data, contributed to the manuscript, JR obtained research funding, contributed to the manuscript, AN designed the study, supervised data collection and cleaning, obtained all local approvals for the study, contributed to data analyses and manuscript preparation. The author(s) read and approved the final manuscript.

\section{Funding}

The investigators were supported by the following grants: National Institutes of Health: R01 DA030778 (J.R.), K24 DA022122 (J.R.), P30 Al042853 (J.R.), K23 Al112477 (A.N.), R34 DA045592 (A.N.), CTSA UL1-RR024982.

\section{Availability of data and materials}

The datasets generated and analysed during the current study are not publicly available due the fact that the data come from multiple sources and are covered under multiple different data use agreements but are available from the corresponding author on reasonable request.

\section{Ethics approval and consent to participate}

This study was approved by the Institutional Review Board at University of Texas Southwestern Medical Center. Additional approvals were also obtained from Parkland Health and Hospital Systems and the Dallas County Jail.

\section{Consent for publication}

N/A

\section{Competing interests}

AN receives research funding from Gilead FOCUS program. No other authors had conflicts of interest.

\section{Author details}

${ }^{1}$ Stanford University Medical Center, Palo Alto, CA, USA. ${ }^{2}$ Department of Clinical Sciences, University of Texas Southwestern Medical Center, Dallas, TX, USA. ${ }^{3}$ Department of Internal Medicine and Epidemiology, Warren Alpert Medical School of Brown University, Providence, RI, USA. ${ }^{4}$ Department of Internal Medicine, Division of Infectious Diseases, University of Texas Southwestern Medical Center, 5323 Harry Hines Blvd., Dallas, TX 75390-9169, USA. ${ }^{5}$ Parkland Health and Hospital Systems, Dallas, TX, USA.

Received: 16 December 2019 Accepted: 18 June 2020

Published online: 27 June 2020

\section{References}

Althoff, A. L., Zelenev, A., Meyer, J. P., Fu, J., Brown, S. E., Vagenas, P., et al. (2013). Correlates of retention in HIV care after release from jail: Results from a multisite study. AIDS and Behavior, 17(Suppl 2), S156-S170. https://doi.org/10.1007/ s10461-012-0372-1.

Ammon, B., Iroh, P., Tiruneh, Y., Li, X., Montague, B. T., Rich, J. D., \& Nijhawan, A. E. (2018). HIV care after jail: Low rates of engagement in a vulnerable population. Journal of Urban Health, 95(4), 488-498. https://doi.org/10.1007/ s11524-018-0231-0.

Ballard, D. W., Price, M., Fung, V., Brand, R., Reed, M. E., Fireman, B., et al. (2010). Validation of an algorithm for categorizing the severity of hospital emergency department visits. Medical Care, 48(1), 58-63. https://doi.org/10. 1097/MLR.0b013e3181bd49ad.

Beckwith, C. G., Nunn, A., Baucom, S., Getachew, A., Akinwumi, A., Herdman, B., et al. (2012). Rapid HIV testing in large urban jails. American Journal of Public Health, 102(Suppl 2), S184-S186. https://doi.org/10.2105/AJPH.2011.300514.

Boyd, A. T., Song, D. L., Meyer, J. P., \& Altice, F. L. (2015). Emergency department use among HIV-infected released jail detainees. Journal of Urban Health, 92(1), 108-135. https://doi.org/10.1007/s11524-014-9905-4.

Bracken, N., Hilliard, C., McCuller, W. J., \& Harawa, N. T. (2015). Facilitators of HIV medical care engagement among former prisoners. AIDS education and prevention: official publication of the International Society for AIDS Education, 27(6), 566-583. https://doi.org/10.1521/aeap.2015.27.6.566.

Bronson, M. (2017). HIV in prisons, 2015 - Statistical tables. Washington, DC. Retrieved from https://www.bjs.gov/index.cfm?ty=pbdetail\&iid=6026.

Chaudhri, S., Zweig, K. C., Hebbar, P., Angell, S., \& Vasan, A. (2019). Traumainformed care: A strategy to improve primary healthcare engagement for persons with criminal justice system involvement. Journal of General Internal Medicine, 34(6), 1048-1052. https://doi.org/10.1007/s11606-018-4783-1.

Dumont, D. M., Brockmann, B., Dickman, S., Alexander, N., \& Rich, J. D. (2012). Public health and the epidemic of incarceration. Annual Review of Public Health, 33, 325-339. https://doi.org/10.1146/annurev-publhealth-031811124614.

Flash, C. A., Pasalar, S., Hemmige, V., Davila, J. A., Hallmark, C. J., McNeese, M., et al. (2015). Benefits of a routine opt-out HIV testing and linkage to care program for previously diagnosed patients in publicly funded emergency departments in Houston, TX. Journal of Acquired Immune Deficiency Syndromes, 69(Suppl 1), S8-S15. https://doi.org/10.1097/qai. 0000000000000578

Frank, J. W., Andrews, C. M., Green, T. C., Samuels, A. M., Trinh, T. T., \& Friedmann, P. D. (2013). Emergency department utilization among recently released prisoners: A retrospective cohort study. BMC Emergency Medicine, 13, 16. https://doi.org/10.1186/1471-227x-13-16.

Friedman, E. G., Crowley, M., Howard, K. A., \& Pavel, M. P. (2015). Home improvement in HIV primary care: Investigating the patient-centered medical home model for people living with HIV/AIDS. Population Health Management, 18(5), 323-329. https://doi.org/10.1089/pop.2014.0150. 
Glaze, L.E., \& Hereberman, E.J. (2013). Correctional populations in the United States, 2012. Bureau of Justice Statistics. December 2013, NCJ 243926. Report retrieved from: https://www.bjs.gov/content/pub/pdf/cpus12.pdf.

Grodensky, C. A., Rosen, D. L., Blue, C. M., Miller, A. R., Bradley-Bull, S., Powell, W. A. , et al. (2018). Medicaid enrollment among prison inmates in a nonexpansion state: Exploring predisposing, enabling, and need factors related to enrollment pre-incarceration and post-release. Journal of Urban Health, 95(4), 454-466. https://doi.org/10.1007/s11524-018-0275-1.

Guyer, J., Serafi, K., Bachrach, D., \& Gould, A. (2019). State strategies for establishing connections to health care for justice-involved populations: The central role of medicaid. Issue Brief (Commonwealth Fund), 2019, 1-12.

Iroh, P. A., Mayo, H., \& Nijhawan, A. E. (2015). The HIV care cascade before, during, and after incarceration: A systematic review and data synthesis. American Journal of Public Health, 105(7), e5-e16. https://doi.org/10.2105/ajph.2015. 302635.

Johnston, K. J., Allen, L., Melanson, T. A., \& Pitts, S. R. (2017). A "patch" to the NYU emergency department visit algorithm. Health Services Research, 52(4), 12641276. https://doi.org/10.1111/1475-6773.12638.

Khanna, S., Leah, J., Fung, K., Antoniou, T., \& Kouyoumdjian, F. (2019). Health care utilization by people with HIV on release from provincial prison in Ontario, Canada in 2010: A retrospective cohort study. AIDS Care, 31(7), 785-792. https://doi.org/10.1080/09540121.2018.1556383.

Loeliger, K. B., Meyer, J. P., Desai, M. M., Ciarleglio, M. M., Gallagher, C., \& Altice, F. L. (2018). Retention in HIV care during the 3 years following release from incarceration: A cohort study. PLoS Medicine, 15(10), e1002667. https://doi. org/10.1371/journal.pmed.1002667.

MacGowan, R. J., Lifshay, J., Mizuno, Y., Johnson, W. D., McCormick, L., \& Zack, B. (2015). Positive transitions (POST): Evaluation of an HIV prevention intervention for HIV-positive persons releasing from correctional facilities. AIDS and Behavior, 19(6), 1061-1069. https://doi.org/10.1007/s10461-0140879-8

Maruschak, L.M. (2015) HIV in Prisons, 2001-2010. Bureau of Justice Statistics. September 2012, revised March 24, 2015, NCJ 238877. Report retrieved from: https://doi.org/10.1186/s40352-020-00118-2. https://www.bjs.gov/content/ pub/pdf/hivp10.pdf.

Meyer, J. P., Qiu, J., Chen, N. E., Larkin, G. L., \& Altice, F. L. (2013). Frequent emergency department use among released prisoners with human immunodeficiency virus: Characterization including a novel multimorbidity index. Academic Emergency Medicine, 20(1), 79-88. https://doi.org/10.1111/ acem. 12054

Mignon, S. (2016). Health issues of incarcerated women in the United States. Ciência \& Saúde Coletiva, 21(7), 2051-2060. https://doi.org/10.1590/141381232015217.05302016.

Montague, B. T., Rosen, D. L., Sammartino, C., Costa, M., Gutman, R., Solomon, L., \& Rich, J. (2016). Systematic assessment of linkage to care for persons with HIV released from corrections facilities using existing datasets. AIDS Patient Care and STDs, 30(2), 84-91. https://doi.org/10.1089/apc.2015.0258.

Pew Charitable Trusts, T. (2011). State of recidivism: The revolving door of America's prisons. Washington, D.C. Retrieved from https://www.pewtrusts. org/en/research-and-analysis/reports/0001/01/01/state-of-recidivism

Sayles, J. N., Wong, M. D., Kinsler, J. J., Martins, D., \& Cunningham, W. E. (2009). The association of stigma with self-reported access to medical care and antiretroviral therapy adherence in persons living with HIV/AIDS. Journal of General Internal Medicine, 24(10), 1101-1108. https://doi.org/10.1007/s11606009-1068-8

Sharma, S. M. T., Seals, N., Jenkins, K., Isaacs, M., \& Anderson, R. J. (2017). High frequency patient analysis to identify disparities associated with emergency department utilization in Dallas County. Texas Public Health Journal, 69, 1929.

Spaulding, A. C., Kim, M. J., Corpening, K. T., Carpenter, T., Watlington, P., \& Bowden, C. J. (2015). Establishing an HIV screening program led by staff nurses in a county jail. Journal of public health management and practice: JPHMP, 21(6), 538-545. https://doi.org/10.1097/PHH.0000000000000183.

Spaulding, A. C., Messina, L. C., Kim, B. I., Chung, K. W., Lincoln, T., Teixeira, P., et al. (2013). Planning for success predicts virus suppressed: Results of a noncontrolled, observational study of factors associated with viral suppression among HIV-positive persons following jail release. AIDS and Behavior, 17(Suppl 2), S203-S211. https://doi.org/10.1007/s10461-012-0341-8.

Subramanian, R, Henrichson, C., Kang-Brown, J. (2015). In our own backyard: Confronting growth and disparities in American jails. Retrieved from https:// www.vera.org/downloads/publications/incarceration-trends-in-our-ownbackyard-fullreport.pdf

Washington Post Editorial Board, T. (2019, May 12). It's time to end the callous policy of inmate Medicaid exclusion. The Washington Post Retrieved from https://www.washingtonpost.com/opinions/its-time-to-end-the-callouspolicy-of-inmate-medicaid-exclusion/2019/05/12/9f69c7d4-4cd2-11e9-966300ac73f49662_story.html.

Westergaard, R. P., Spaulding, A. C., \& Flanigan, T. P. (2013). HIV among persons incarcerated in the USA: A review of evolving concepts in testing, treatment, and linkage to community care. Current Opinion in Infectious Diseases, 26(1), 10-16. https://doi.org/10.1097/QCO.0b013e32835c1dd0.

Wohl, D. A., Golin, C. E., Knight, K., Gould, M., Carda-Auten, J., Groves, J. S., et al. (2017). Randomized controlled trial of an intervention to maintain suppression of HIV Viremia after prison release: The imPACT trial. Journal of Acquired Immune Deficiency Syndromes, 75(1), 81-90. https://doi.org/10.1097/ qai.0000000000001337

Wohl, D. A., Scheyett, A., Golin, C. E., White, B., Matuszewski, J., Bowling, M., et al. (2011). Intensive case management before and after prison release is no more effective than comprehensive pre-release discharge planning in linking HIV-infected prisoners to care: A randomized trial. AIDS and Behavior, 15(2), 356-364. https://doi.org/10.1007/s10461-010-9843-4.

\section{Publisher's Note}

Springer Nature remains neutral with regard to jurisdictional claims in published maps and institutional affiliations.
Ready to submit your research? Choose BMC and benefit from:

- fast, convenient online submission

- thorough peer review by experienced researchers in your field

- rapid publication on acceptance

- support for research data, including large and complex data types

- gold Open Access which fosters wider collaboration and increased citations

- maximum visibility for your research: over $100 \mathrm{M}$ website views per year

At $\mathrm{BMC}$, research is always in progress.

Learn more biomedcentral.com/submissions 